\title{
Professionals' perceptions about the need for pain management interventions for children with cerebral palsy in South African school settings
}

\author{
Stefan Nilsson, $\mathrm{RN}, \mathrm{PhD}^{1^{*}}$, Ensa Johnson, $\mathrm{PhD}^{2}$, Margareta Adolfsson, $\mathrm{PT}, \mathrm{PhD}^{3}$ \\ ${ }^{1}$ CHILD, Institute of Health and Care Sciences, University of Gothenburg, Gothenburg, Sweden \\ ${ }^{*}$ Address correspondence to Stefan Nilsson, RN, PhD, CHILD, Institute of Health and Care Sciences, \\ University of Gothenburg, Box 457, 40530 Gothenburg, Sweden. \\ ${ }^{2}$ Centre for Augmentative and Alternative Communication, University of Pretoria, South Africa \\ ${ }^{3} \mathrm{CHILD}$, School of Education and Communication and the Swedish Institute of Disability Research, University \\ of Jönköping, Jönköping, Sweden
}

\section{Abstract}

Background: Pain is common in children with cerebral palsy (CP) and may have negative consequences for children's success in their studies. Research has shown that pain in childhood negatively influences individuals’ participation and quality of life in later years. Aim: This study investigated how professionals in South African school settings respond to children's need for pain management in an attempt to enable the children to be active participants in school activities, despite their pain.

Design: The study was descriptive and followed a qualitative design, i.e. focus group interviews with semi structured questions and a conventional content analysis.

Settings: Five government schools for children with special education needs in South Africa’s Gauteng province.

Participants/Subjects: Thirty-eight professionals who represented eight professions. Methods:

Data, in terms of professional statements on the topic, were collected from five focus group sessions conducted during one week. Qualitative content analysis was used to analyze the data. Similar statements were combined, coded, and sorted into main categories and subcategories.

Results: The analysis identified three main categories for pain management: environmental, treatment, and support strategies. In addition, four groups of statements emerged on how contextual factors might affect pain in children with CP and their participation in school settings. 
Conclusions: It is important to train professionals in pain management and to implement structured models for pain prevention and management to ensure that best practices are adhered to for children with CP who suffer from acute or chronic pain.

\section{Scenario summary}

- Pain management involved environmental, treatment, and support strategies by professionals.

- Both educators and therapists would benefit from training in everyday pain management.

- Professionals perceived inadequate access to resources.

- Older children could be neglected when available resources were used for younger children.

- A standardized follow-up model to prevent pain was lacking.

\section{Background}

Pain can influence a child's independence and participation at school and in the community. It has been established that pain in childhood will have a negative impact on an individual's participation in and quality of life in later years (Colver et al., 2015; Vargus-Adams \& Martin, 2011). Children with cerebral palsy (CP) who attend school have to overcome special challenges to succeed in their studies. These may result from pain affecting their attention or be due to their inability to express pain (Engel \& Kartin, 2006; Johnson, Nilsson, \& Adolfsson, 2015). It is therefore important that all professionals who work with children with CP acknowledge and manage the children's pain to ensure optimal learning opportunities and participation in classroom activities. As far as we know, no previous research has focused on this topic. 
The aim of this study was to investigate how professionals in South African school settings respond to the need for pain management interventions for children with $\mathrm{CP}$ in their attempt to enable the children to be active participants in school activities, despite their pain. The following research question was addressed: Which strategies and actions for pain management do professionals use in South African school settings to try to support children with CP to become active participants in school activities, despite acute and chronic pain? Two sub questions concerned how the professionals act when a child with CP is in pain and which other strategies they have tried to manage pain in children with CP.

\section{Literature Review}

CP includes a group of permanent disorders with specific neurological signs, such as ataxia, dystonia, and spasticity. Individuals with CP have varying levels of communication abilities, and the abnormal muscle tone affects gross and fine motor abilities, which in turn influence movement and posture (Rosenbaum, Paneth, Leviton, Goldstein, \& Bax, 2007; Westbom, Hagglund, \& Nordmark, 2007). Musculoskeletal and gastrointestinal pain can be caused by spasticity combined with an inability to change position and reduce pressure on certain body parts. Research has found that $60 \%$ of children with CP aged 8 to 12 years reported pain during a one-week period, however, not necessarily related to the severity of the CP (Parkinson, Gibson, Dickinson, \& Colver, 2010).

Pain has different causes and manifests itself in different ways. By definition, it is “an unpleasant sensory and emotional experience associated with actual or potential tissue damage or described in terms of such damage” (IASP, 1994). Acute pain may be caused by an accident or trauma, and procedural pain appears in conjunction with treatment or examination in hospital. Both kinds of pain can be reduced using medication such as analgesics and 
sedatives. The pain disappears when the body tissue is healed or the treatment is completed (Harstall \& Ospina, 2003). Chronic pain, however, is beyond normal tissue healing.

For children with CP, chronic pain is a common condition that may reduce their quality of life (Dickinson et al., 2007; Ramstad, Loge, Jahnsen, \& Diseth, 2014). One example is that, due to recurrent musculoskeletal pain, the children can experience problems with peer relationships.

In South Africa, children with CP usually attend special education schools. The neurological disorder occurs in $8.4 \%$ of children with intellectual disabilities (Christianson et al., 2002). In attempts to correct and rehabilitate orthopedic problems, such as hip dislocations, children with CP often undergo surgical and medical procedures and interventions that may alleviate frequent pain in the long run (Engel \& Kartin, 2006; Ramstad, Jahnsen, Skjeldal, \& Diseth, 2011). However, painful experiences may arise during procedures such as needle injections, range of motion/movement manipulation, and assisted stretching (Swiggum, Hamilton, Gleeson, \& Roddey, 2010). In conjunction with such procedures, professionals have an essential role in pain management (Bice, Gunther, \& Wyatt, 2014). Their knowledge, combined with protocols to optimize pain assessment and the pain medication given, ensures pain relief for the children.

Pain often causes sleep problems, tiredness, and decreased well-being. This may hamper participation in everyday life activities, such as with family and at school, and other social events, for children with CP (Beckung \& Hagberg, 2002; Jemta, Dahl, Fugl-Meyer, \& Stensman, 2005). In addition, they use a large amount of energy in attempts to report the pain, which distracts their attention from the activity at hand (Castle, Imms, \& Howie, 2007). As participation in everyday activities helps children to develop and become independent members of a society, it is important to pay special attention to this group of children. If pain in early ages becomes an obstacle, it may influence the children's ability to participate in 
social activities during adolescence and, subsequently, their perception of quality of life (Colver et al., 2015; Dang et al., 2014). Children’s participation in everyday activities is also influenced by environmental factors, such as access to public and health services due to availability in general or in the local area where they live. Other environmental issues include accommodation strategies (e.g., ramps to enter buildings), treatment by therapists or educators, attitudes of educators, and, typically, developing relationships with peers in school settings. If unsupportive, these environmental factors can restrict children with disabilities from participating in everyday activities (Bedell et al., 2013). Such restrictions can also be a result of insufficient knowledge about pain management or how to cope with children with complex communication needs (Bornman \& Donohue, 2013). A need for improved attitudes and knowledge about pain and pain management among nurses has been shown in several countries, including South Africa (Enskär et al., 2007; Thunberg, Buchholz, \& Nilsson, 2015; Twycross \& Collis, 2013). However, it is not known how other professionals working in South African school settings provide pain management interventions for children with CP.

Professionals should use different treatment strategies for every child, i.e., an individual combination of pharmacological substances and complementary methods that include psychological, social, and physical strategies such as physiotherapy (Nilsson, Enskär, Hallqvist, \& Kokinsky, 2013; Penner, Xie, Binepal, Switzer, \& Fehlings, 2013). As orally administered medication does not always reduce pain in children with $\mathrm{CP}$, alternatives could be implemented with other types of medication, such as continuous intrathecal baclofen (CITB) therapy (Vles et al., 2013) or botulinum toxin type-A (BoNT-A; Williams et al., 2013). Examples of complementary methods that could be implemented are strength training to manage spasticity and muscle weakness (Williams et al., 2013), massage therapy (Nilsson, Johansson, Enskär, \& Himmelmann, 2011), selective dorsal rhizotomy for reducing muscle spasticity, casting for improving and maintaining ankle range of motion, and 
neurodevelopmental treatment (NDT), also known as the Bobath concept. NDT includes facilitating handling techniques related to positioning and is commonly implemented for specific functional tasks aimed at treating children in actual life settings, i.e., where they live, play, and learn (Novak et al., 2013). Another strategy is to use a standardized, systematic follow-up surveillance program. Such a program for children with CP (CPUP) was introduced in Sweden two decades ago (Hagglund et al., 2014) and has since successfully addressed the prevention of hip dislocations (Larnert, Risto, Hagglund, \& Wagner, 2014).

Not all treatment methods have been efficient. NDT, for example, is neither more nor less effective than other methods and is not recommended as standard care for children with CP (Novak et al., 2013). Most studies on NDT have showed serious methodological concerns, i.e., it was unclear whether measures were meaningful to the client and sensitive to clinical change, which has led to an unclear clinical direction (Vaughan-Graham, Cott, \& Wright, 2015b). Despite the treatment method, research has shown that children with CP, as well as their relatives, regard the treatment of pain as an important issue to assist children's functioning at school (Berrin et al., 2007).

\section{Methods}

The study was part of a larger project conducted by the Centre for Augmentative and Alternative Communication (CAAC) at the University of Pretoria in South Africa, in collaboration with the Children, Health, Intervention, Learning, Development (CHILD) research group at the University of Jönköping in Sweden. The larger project aimed to study how children with CP in Sweden and South Africa are supported in school settings, with the overall purpose of identifying effective routines and niches where cultural diversity can have a stimulating effect on pain management. The first study was about pain communication 
(Johnson, Nilsson, \& Adolfsson, 2015) whereas the present study specifically focuses on pain management strategies.

The study was descriptive and followed a qualitative design with semi structured questions used during interactive focus group interview sessions to obtain information on the situation of children with CP in South African schools.

\section{Participants}

Five government schools for children with special education needs that accommodate children with CP situated in Pretoria and Johannesburg (Gauteng, South Africa) participated in five focus group interview sessions. The schools varied in size, age of the children, number of children in hostels, proportion of children with CP, and staff composition (Table 1). Orthopedic surgeons were linked to all the schools as consultants.

Altogether, 38 professionals (aged 22-64 years; $M=44.4$ years; SD=11.9) who represented eight professions participated in the focus groups (Table 2). Of the participants, 26 were therapists, 11 educators, and one a personal assistant. The therapists saw the children in the classroom and treated them in the therapy rooms at the schools. All the professional participants were women, except the personal assistant, who also had a sister with severe CP. The professionals' level of education was high (76\% had four or more years' university training and $11 \%$ had additional training in NDT) and their professional experience of working with children with CP was extensive (M=11.8 years; SD 9.2).

\section{Procedure}

Data in terms of professional statements on the topic were collected from five focus group interview sessions conducted during one week in February 2014. Consent was given by the 
principals, who had been informed orally and in writing about the study. The principals identified suitable participants for the focus group interviews. All the participants received written information about the study and agreed to participate by means of informed written consent.

The decision to use focus groups was made because the group dynamic could stimulate discussions and pursue a topic in greater depth than would have been collected through other methods, such as surveys or individual interviews (White \& Verhoef, 2005; Wibeck, Abrandt Dahlgren, \& Öberg, 2007). The open questions, the interaction with other participants, and the moderator's neutral role intended to challenge the participants and provide opportunities for them to revise and expand their opinions (Sandelowski, 1993; White \& Verhoef, 2005).

A focus group interview guide and demographic information questionnaire were developed in English and pilot tested in South Africa with four therapists and two educators. After the pilot test, minor amendments were made to the interview guide. As the questions were well understood, despite several participants having other first languages than English, it was decided to include the data of the pilot study in the results of the main study.

The focus group interview sessions included two identically applied parts focusing on pain assessment and pain management respectively. The duration of the sessions varied between 70 and 110 minutes. For the purpose of this study, data about pain management interventions, i.e., strategies and actions, were considered and collected primarily during the second part of the sessions. One broad question was introduced for this study: Which strategies and actions for pain management do you use to try to support children with CP to become active participants in the school activities, despite acute and chronic pain? Two sub questions were added: (1) How would you act when a child with CP is in pain? (2) Which other strategies have you tried to manage pain in children with CP? 
The procedure for the focus group sessions was agreed on beforehand. The third author, a Swedish physiotherapist with experience of working with children with disabilities as well as conducting focus groups, acted as moderator (Wibeck, 2010). The second author, a South African special educator who specializes in pain communication, entered all the comments on a laptop. If the participants had problems expressing some words in English, she supported them in Afrikaans. The comments were projected onto a wall that the participants could check continuously. The first author, a Swedish pediatric nurse who specializes in pain management, audio-recorded the discussions, reflected on all the statements, and concluded the sessions by asking for more information about possible missing data. The audio-recorded material was used to update the researchers on the discussions during data analysis. In each focus group, the discussions were interrupted after about 30 minutes, and all the statements were then jointly reviewed and revised where necessary. As part of this member check, which is a method purposed to provide a possibility to obtain additional information or to correct data (Morse, 2015), the participants indicated that the statements truly represented their experiences and added information where applicable.

\section{Data analysis}

Conventional content analysis based on Hsieh and Shannon (2005) was used. After each focus group discussion, statements were entered onto a spreadsheet and jointly coded by the first and third authors. On completion of the data collection, all codes from the five focus groups were gathered in a single spreadsheet. Reductions were made due to the deletion of duplications and statements that were too general or not related to CP or pain management. Thereafter, the second author reviewed the coding. All three researchers discussed discrepancies until agreement had been obtained. Accordingly, the identified codes were independently verified by peer researchers, which strengthened their credibility (Graneheim Hällgren \& Lundman, 2004). Codes relating to the research question were jointly sorted into 
subcategories that were merged into main categories. The results were compared with the original data at each level of abstraction to guarantee that trustworthiness was achieved. To achieve credibility the authors compared and discussed each step of the analysis until consensus was reached (Morse, 2015).

Statements that were not directly connected to the research question but included contextual and cultural information of importance to a child's participation in school activities were considered as “context.” The information intended to support the researchers' understanding of contextual factors that might affect the children's pain and thus their participation. These contextually based statements were grouped and coded to provide a background to the children’s everyday lives.

\section{Ethical consideration}

Ethics approval was obtained from the Ethics Committee of the Faculty of Humanities at the University of Pretoria and the Gauteng Department of Education before any recruitment of participants commenced.

\section{Results}

The results focus on how professionals responded to the need for pain management interventions for the children.

Fourteen subcategories were identified as strategies employed by educators and therapists (Table 3). The subcategories, which showed what was performed by the professionals, were merged into three main categories, which are described briefly below. Additional contextual information to provide background on the South African context and put the results into a wider context was grouped into four supplementary codes (Table 4). 


\section{Environmental strategies}

The first main category reflects how professionals' interventions influenced the children's environment at school and at home. It concerned adaptations of equipment and support of networks aiming to prevent or minimize pain in children with CP (Table 3).

Assistive devices, such as adapted chairs and wheelchairs, wheelchair tables, pillows, and standing frames, were used to facilitate the children's functioning. The school schedule and activities were adapted and organized so that the children could use the same classroom for the whole day, or a child with severe CP and chronic pain could lie on a bed in the classroom if necessary.

The children's peers were encouraged to play an active role in providing pain relief to some extent. For example, they helped their classmate to be more comfortable, such as to straighten up or to get into a better sitting with the help of a pillow. They also alerted the educator that the child seemed to be in pain and maybe needed to be sent to a therapist.

The therapists transferred knowledge to educators and class assistants to ensure satisfactory pain management and thus increase the educators' involvement in the pain management process.

Therapists collaborated with parents and personnel at the hostels for the purpose of accommodating the children outside of the school environment to contribute to good conditions for the children's participation in school activities. They offered training and group activities as support in the pain management. It was explained that the children with CP were often kept in bed for the duration of holidays, making their limbs stiff or reducing their range of movement due to lack of exercise. 


\section{Treatment strategies}

The second main category included "hands-on" treatment strategies used by professionals to manage pain identified in children with CP (Table 3). Pain treatment was mainly nonpharmacological.

Stretching and positioning were common pain-relieving strategies. Therapists, such as occupational, physio-, and speech-language therapists, often mentioned positioning as extremely important and talked about the advantage of NDT. Individualized splints were used to stretch muscles and prevent contractures. In severe cases, therapists provided relaxation treatment strategies, such as massages or warm baths, to relieve the pain.

Medication was administered infrequently. Participants usually treated pain that had already appeared and reported that they avoided giving analgesics due to the possible side effects, such as tiredness and dizziness. They rarely used medication for prevention of pain and did not report on any standardized prevention or follow-up program. Some claimed that they did not think that the children needed pain relief treatment, i.e., they stated that children with CP did not complain about their pain and became used to their pain. Other statements claimed that participants judged the child's complaint about pain as an attempt to get attention from the adults, and in these circumstances a glass of water often replaced analgesics. When analgesics were administrated, paracetamol (such as Panado) and non-steroidal antiinflammatory drugs (NSAID) were used most often. A physician's prescription was needed to enable nurses to provide these drugs or other medication to the children for a prolonged period. Nevertheless, participants said that analgesics sometimes helped to reduce the children's pain and improved their activity and participation in the school setting.

\section{Support strategies}

Professionals' support strategies was the third main category (Table 3). It illustrated how the professionals actively played a supportive role in pain management. 
Distraction techniques were used, such as joking with the child or trying to let the child focus on other stimuli: "They love a bandage and a plaster” (although they have no use). In class, educators used positive encouragements to try to distract children from pain and focus on their school work. When distraction techniques were not effective and further treatment was necessary, a child sometimes had to be sent to the therapy rooms, resulting in the child not being able to participate fully in the school activities.

Before treatment, the participants prepared the children for exercises that might be painful. They explained why the activities were necessary and encouraged the children by means of palliative reassurances such as We know what you are going through; it is tough; we are here to assist, but you need to finish the activity. During treatment, emotional support and encouragement were provided with remarks such as: I have a lot of empathy with you, but you must try to get through it Gr 12.

Professional team collaboration within schools was a strategy to support the children. The educators received assistance from the therapists in the classroom if they were not able to comfort a child themselves. When the therapists in the schools considered their efforts to reduce the child's pain unsuccessful, they referred the child to external professionals, such as physicians or orthopedic doctors, to assist with the treatment.

\section{Contextual factors}

Professionals' statements that emerged from cultural and contextual information showed how contextual factors might affect the children's pain and thus their participation in school activities. Four groups of statements were identified and coded: children’s adjustment to pain, cultural attitudes towards disability, transportation, and resources. Table 4 illustrates the content of these codes. For example, the professionals assumed that children were concerned 
about being taken out of class due to pain and thereby not being able to learn. Children with disabilities were kept at home instead of being sent to school and treated by religious healers rather than medical doctors. A non-disability-friendly transportation system caused the children extra pain due to long waits for a taxi. Statements also concerned the resources needed to relieve the professionals' caseloads and enable them to provide all children with good care in the school settings, for example, not having to prioritize younger children over older ones and time for training and information to new staff members on how to handle a child in pain. Other statements were about unequal access to medication, much due to financial constraints, and the time it could take before a child got an appointment at the hospital. For example, long waiting lists for surgery of dislocated hips caused the need of extensive pain medication, which was deemed as harmful.

\section{Discussion}

The main findings from this study concerned pain management strategies that professionals in a sample of South African schools gave to individual children to promote their participation in the school setting. Three identified strategies reflected the actions professionals used; environmental, treatment, and support strategies. As the participants had no access to any standardized follow-up program, most of the pain management strategies rather focused on pain that had appeared than on prevention of pain. Additional information supported the researchers' understanding of contextual factors that might affect the children's pain and thus their participation. The influence of contextual factors, such as culture, transport and lack of resources also affected the management of pain in children with CP in South African school settings. 


\section{Focus group interviews}

By providing the focus group as a forum for professionals from different disciplines in a school to meet in, they learned from one another about pain management. Pain in children with CP seemed to be an unfamiliar subject for discussion but was facilitated by the questions asked. In the beginning of the focus group interview sessions the participants for example mentioned that they could not always observe and realize when a child was in pain or know exactly where the pain was located. This might threaten proper pain management, because it is known that professionals' individual opinions and attitudes influence the pain management of children (Bice et al., 2014). The lack of pain identification therefore emphasizes the need for professional education as well as the development of measurements and protocols to optimize pain management interventions (de Freitas et al., 2014).

After interactive discussions between the participants in the focus groups, they seemed to realize that although pain episodes are not necessarily explained as being part of the diagnosis, most children with CP do experience pain on a daily basis (Parkinson, Gibson, Dickinson, \& Colver, 2010). After a while, several examples of pain management strategies were shared, and it was obvious that pain management was given by professionals without much reflections. The professionals noticed both acute and chronic pain as common issues in children with CP, which also has been highlighted in earlier research (Parkinson, Gibson, Dickinson, \& Colver, 2010).

\section{Pain management strategies}

Several actions in terms of environmental, treatment, and support strategies to relieve pain were discussed. They also referred to other considerations, for example, tiredness and dizziness, which should be taken into account when trying to relieve pain in children with CP (Kozlowski et al., 2014). These symptoms are often seen as side effects of chronic pain, and more rarely of analgesics such as NSAIDs (Titchen, Cranswick, \& Beggs, 2005; Vogtle, 
Malone, \& Azuero, 2014). This showed a need for a broader knowledge about pharmacological pain treatment as one possible pain management intervention.

The participants reported actions that focused on how the children's environment could provide support. This pointed to a multidisciplinary approach to pain management, which is an important approach in the treatment of chronic pain (Castle et al., 2007; Forgeron \& Stinson, 2014). Complementary accommodations most often contribute to the alleviation of a child's pain better than the use of only one at a time. In addition, the support of networks to compensate for impaired physical capacities, such as movement and posture, can both reduce pain and increase a child's independence (Bornman \& Rose, 2010). Fortunately, the findings establish that the participants took advantage of the benefits of assistive products and adapted schedules. They were also aware of how an integration of whole networks in everyday pain management would strengthen the children's educational environments. Unfortunately it seemed like their caseloads entailed limited space for training and collaboration.

Hands-on treatment strategies were based on the professionals' current knowledge. They applied their own best practices, although there could sometimes be a gap between evidence and practice. An example is that the therapists frequently referred to NDT and demanded more educated NDT therapists, despite the lack of evidence of the method's impact on pain (Novak et al., 2013). The principles of NDT need further clarification, and future studies are required to investigate the effectiveness of the method in clinical practice (Vaughan-Graham, Cott, \& Wright, 2015a). Meanwhile, professionals should be offered training in various, equally - or more - effective pain management approaches.

The participants perceived that they played an active, supportive role in the pain management through, for example, distraction and emotional accounts. As stressed by Bice et al. (2014), professionals have an essential role in pain management, but lack of time and knowledge can 
hinder their own ability to support or treat a child properly. It was therefore reassuring that the participants in this study were aware of the option to refer the children with the most severe problems to external doctors even though it could harm a child's participation in school activities. It would provide the child supplementary interventions in terms of medication and/or surgery.

\section{Contextual factors}

Some of the statements included information about how the culture and the context in which the children lived would affect their pain. Although not possible to categorize as pain management strategies, these contextual factors supported the researchers' understanding of children with CP's participation in school settings despite pain.

The participants stated that children with CP seemed to become used to their pain, although they never questioned the possibility that the children might actually have experienced acute or chronic pain. The children were considered to be dedicated to their work in class and therefore did not complain about pain for fear of having to go to the nurse or therapist for pain treatment and miss out on their classwork. It is possible that the children who did not complain were incorrectly perceived by the professionals as coping with their pain. According to Schiavenato and Craig (2010), the absence of complaints might be due to previous attempts to communicate pain having been neglected by the people around the children, resulting in them giving up on attempts to communicate their pain experiences. As previous studies suggest (Lazarus, 2006; Nilsson et al., 2011), an optimistic explanation could be that these children had developed reasonably effective coping strategies that limited their pain experiences to enable them to stay in class and participate in the ongoing activities. A less optimistic alternative explanation could be that boys with CP did not complain, because in some South African cultures, such as Sotho and Nguni, it is unacceptable for boys (and men) to cry, as this is regarded as a sign of weakness or lack of courage and honor (Nortjé \& 
Albertyn, 2015). In this regard, it is important that professionals are made aware of cultural differences in order to be able to detect pain in a child and provide support. Another cultural influence may mean that it can be disgraceful to ask for pain relief, and, in some cultures, people believe that godly intervention will relieve pain when appropriate (Briggs, 2010; Nortjé \& Albertyn, 2015). Such cultural influences can cause children to avoid expressing their pain or asking for pain relief medication.

BoNT-A and CITB are examples of treatments that evidently reduce pain in children (Pin, Elmasry, \& Lewis, 2013; Vles et al., 2013). Unfortunately, children with CP in South Africa often had to wait very long periods for medical appointments, and they lacked medical treatment in terms of evidence-based medicine, such as BoNT-A (Williams et al., 2013) and CITB (Vles et al., 2013). Our study showed that it was a challenge to access this kind of medication, mostly due to financial constraints. The inadequate access to resources, perceived by the participants in this study, affected pain management negatively in the children with CP.

Sufficient resources of various kinds are necessary to support children with CP who are in pain in the best possible ways. The professionals in this study mentioned that if more assistants were available in schools and hostels, they could reduce the educator's caseloads by helping with the children's pain management and self-care tasks. An assistant can, for example, ensure that a child is positioned correctly or changes position regularly to minimize pain due to pressure on certain body parts (Rivi et al., 2014). The participants were also of the opinion that more therapists could improve the care of the children with CP in the school settings. More therapist time means increased opportunities to transfer knowledge to the network around the child. It means, for example, to inform new educators and guide parents in how to meet a child's needs, which would effectively minimize or prevent pain in both school and home settings (Saloojee, Phohole, Saloojee, \& Ijsselmuiden, 2007). In addition, the shortening of waiting times to extended services such as medication, surgery, and 
rehabilitation would be important means to reduce the harm to children with CP (Larnert et al., 2014) and extend their participation in school activities.

Perceived barriers to adequate service were also related to the therapists' caseloads. Due to lack of time, they could not treat all the children with CP in the school and therefore risked failing in their pain management for the adolescents. A situation demanding tough prioritizations was most obvious in the school with the highest proportion of children with CP and the lowest number of therapists (see Table 1). As it has been established that adolescents with CP who are in pain rate their quality of life lower than their peers without pain (Colver et al., 2015), a failure in pain management might risk their quality of life and these children’s opportunities to acquire knowledge by participating in school activities.

More perceived barriers to adequate service concerned the availability of medical doctors and early childhood interventions. South African legislation stipulates that no pharmacological treatment may be offered without prescription by a doctor (South African Nursing Council, 1984). As long as this legislation lasts, sufficient access to doctors will be rare because of their caseload. About early childhood intervention, a study reported that few South African children received adequate services and that children with disabilities might not have access to treatment early in life (Walker et al., 2011). One reason could be the high level of social stigma towards children with neurological disorders, which results in families failing to seek treatment even when it is available (Donald et al., 2015). This would partly explain why parents take their children to healers. Another reason could be related to the public transport system, which does not accommodate people with disabilities who are in wheelchairs and blocks their access to hospital care facilities. For children with disabilities, inadequate service could most probably also be explained by poor follow-up strategies by the Department of Health. 


\section{Pain prevention}

Pain relief seemed usually provided when pain had already appeared. Based on the experiences from the Swedish CPUP, a standardized surveillance follow-up program to prevent pain would, most probably, be helpful for pain management interventions. The CPUP had prevented painful hip dislocations and reduced the number of children who develop severe contractures, windswept-deformity and scoliosis (Hagglund et al, 2014). In addition, the introduction of CPUP had improved cooperation between children, families, and professionals, and developed a more uniform healthcare in the country. A follow-up program needs to include regular physical assessments of joint range of motion and examination of hips and back but also implement routines for pain assessment, administration of analgesics, and follow-up strategies for the pain management of children with CP in school settings (Hagglund et al., 2014; Twycross, 2013). Such a program could include protocols to optimize pain assessment and pain medication aimed at ensuring pain relief for children and support collaboration with parents/family to ensure consistency of pain management between the school and home (Bice et al., 2014; Hagglund et al., 2014). Overall, a structured program would meet the professionals’ needs for guidance on how to handle a child in pain and support their efforts and everyday procedures to manage the pain and facilitate the children's participation in the school setting.

The use of a standardized follow-up program could also support the professionals to take advantage of all evidence-based models and methods to manage children's pain at an early stage. The implementation of a standardized program requires professional teamwork to guarantee that children with CP receive the best medical treatment available. The participants in this study seemed aware of the advantage of teamwork, and, if effectively implemented, their work could greatly improve the children's participation and quality of life in later years (Colver et al., 2015; Damiano, 2007). An implementation of systematic follow-up programs 
would also highlight the importance of resources in and outside the school settings and maybe also result in more equal access to medication and other treatment.

\section{Limitations}

The study revealed professional strategies and actions for pain management in South African school settings, though, with some limitations. Since only government schools in the Pretoria and Johannesburg areas were included, no information was gathered on potential differences in other schools and regions, such as rural areas. It would also be valuable to take a child's perspective and interview children with CP to enrich the data material. Nevertheless, this study contributes new knowledge about management of chronic pain in children with CP in school settings, since there are no or little previous data about this.

\section{Implications for nursing education, practice, and research}

Education and training in pain management are important issues to ensure that professionals know how to detect pain in children with CP, and that best practices are adhered to for those who suffer from chronic pain.

The use of a structured treatment model and an implemented systematic follow-up program, such as the Swedish CPUP, would benefit children's pain management.

For future research, it would be advantageous to analyze the functionality of pain management strategies and follow-up programs, i.e., how they are directed to increase the children’s attendance in school activities.

It will also be necessary in future research, to investigate some specific interventions for recommendation. The children, who are the ones who experience pain, should evaluate what interventions are most effective. 
We recommend that pain management strategies for children with CP should be investigated in other local schools in South Africa as well as in other parts of the world to determine the best evidence-based practices.

\section{Conclusions}

The main findings from this study concerned environmental, treatment, and support strategies in the frame of additional contextual information. The educators and therapists in South African schools intuitively treated pain when it occurred and took action to relieve it. Pain management interventions would probably be more effective if professionals were offered education to increase their knowledge about pain management and if they had access to an implemented prevention and follow-up program for children with CP. This would develop an evidence-based approach to enable children with CP to be active participants in school activities, despite their pain.

\section{References}

Beckung, E., \& Hagberg, G. (2002). Neuroimpairments, activity limitations, and participation restrictions in children with cerebral palsy. Developmental Medicine \& Child Neurology, 44, 309-316.

Bedell, G., Coster, W., Law, M., Liljenquist, K., Kao, Y. C., Teplicky, R., Anaby, D., \& Khetani, M. A. (2013). Community participation, supports, and barriers of school-age children with and without disabilities. Archives of physical medicine and rehabilitation, 94, 315-323.

Berrin, S. J., Malcarne, V. L., Varni, J. W., Burwinkle, T. M., Sherman, S. A., Artavia, K., \& Chambers, H. G. (2007). Pain, fatigue, and school functioning in children with cerebral palsy: a path-analytic model. Journal of Pediatric Psychology, 32, 330-337. 
Bice, A. A., Gunther, M., \& Wyatt, T. (2014). Increasing nursing treatment for pediatric procedural pain. Pain Management Nursing, 15, 365-379.

Bornman, J., \& Donohue, D. K. (2013). South African Teachers’ Attitudes toward Learners with Barriers to Learning: Attention-deficit and hyperactivity disorder and little or no functional speech. International Journal of Disability, Development and Education, 60, 85-104.

Bornman, J., \& Rose, J. (2010). Believe that all can achieve. Increasing classroom participation in learners with special support needs. Pretoria: Van Shaik.

Castle, K., Imms, C., \& Howie, L. (2007). Being in pain: a phenomenological study of young people with cerebral palsy. Developmental Medicine \& Child Neurology, 49, 445-449.

Christianson, A. L., Zwane, M. E., Manga, P., Rosen, E., Venter, A., Downs, D., \& Kromberg, J. G. R. (2002). Children with intellectual disability in rural South Africa: prevalence and associated disability. Journal of Intellectual Disability Research, 46, 179-186.

Colver, A., Rapp, M., Eisemann, N., Ehlinger, V., Thyen, U., Dickinson, H. O., Parkes, J., Parkinson, K., Nystrand, M., Fauconnier, J., Marcelli, M., Michelsen, S. I., \& Arnaud, C. (2015). Self-reported quality of life of adolescents with cerebral palsy: a crosssectional and longitudinal analysis. Lancet, 385, 705-716.

Damiano, D. (2007). Pass the torch, please! Developmental Medicine and Child Neurology, 49, 723.

Dang, V. M., Colver, A., Dickinson, H. O., Marcelli, M., Michelsen, S. I., Parkes, J., Parkinson, K., Rapp, M., Arnaud, C., Nystrand, M., \& Fauconnier, J. (2014). Predictors of participation of adolescents with cerebral palsy: A European multi-centre longitudinal study. Research in Developmental Disability, 36C, 551-564. 
De Freitas, G. R., de Castro, C. G., Castro, S. M., \& Heineck, I. (2014). Degree of knowledge of health care professionals about pain management and use of opioids in pediatrics. Pain Medicine, 15, 807-819.

Dickinson, H. O., Parkinson, K. N., Ravens-Sieberer, U., Schirripa, G., Thyen, U., Arnaud, C., Beckung, E., Fauconnier, J., McManus, V., Michelsen, S. I., Parkes, J., \& Colver, A. F. (2007). Self-reported quality of life of 8-12-year-old children with cerebral palsy: a cross-sectional European study. Lancet, 369, 2171-2178.

Donald, K. A., Kakooza, A. M., Wammanda, R. D., Mallewa, M., Samia, P., Babakir, H., Bearden, D., Majnemer, A., Fehlings, D., Shevell, M., Chugani, H., \& Wilmshurst, J. M. (2015). Pediatric Cerebral Palsy in Africa: Where Are We? Journal of Child Neurology, 30, 963-971.

Engel, J. M., \& Kartin, D. (2006). Pain in individuals with Cerebral Palsy. In: T. F. Oberlander \& F. J. Symons (Eds.), Pain in children and adults with developmental disabilities (pp. 109-119). Baltimore, Maryland: Paul Brookes Publishing Company. Enskär, K., Ljusegren, G., Gimbler Berglund, I., Eaton, N., Harding, R., \& Mokoena, J. (2007). Attitudes to and knowledge about pain and pain management, of nurses working with children with cancer: A comparative study between UK, South Africa and Sweden. Journal of Research in Nursing, 12, 501-515.

Forgeron, P. A., \& Stinson, J. (2014). Fundamentals of chronic pain in children and young people. Part 1. Nursing Child and Young People, 26, 29-34.

Graneheim Hällgren, U., \& Lundman, B. (2004). Qualitative content analysis in nursing research: concepts, procedures and measures to achieve trustworthiness. Nurse Education Today, 24, 105-112.

Hagglund, G., Alriksson-Schmidt, A., Lauge-Pedersen, H., Rodby-Bousquet, E., Wagner, P., \& Westbom, L. (2014). Prevention of dislocation of the hip in children with cerebral 
palsy: 20-year results of a population-based prevention programme. The Bone and Joint Journal, 96-B, 1546-1552.

Harstall, C., \& Ospina, M. (2003). How prevalent is chronic pain? Pain: Clin Updates, 11.

Hsieh, H., \& Shannon, S. E. (2005). Three approaches to qualitative content analysis.

Qualitative Health Research, 15, 1277-1288.

IASP. (1994). Definition of pain. In: http://www.iasppain.org/AM/Template.cfm?Section=Pain_Definitions\#Pain.

Jemta, L., Dahl, M., Fugl-Meyer, K. S., \& Stensman, R. (2005). Well-being among children and adolescents with mobility impairment in relation to demographic data and disability characteristics. Acta Pcediatrica, 94, 616-623.

Johnson, E., Nilsson, S., \& Adolfsson, M. (2015). Eina! Ouch! Eish! Professionals’ Perceptions of How Children with Cerebral Palsy Communicate About Pain in South African School Settings: Implications for the use of AAC. Augmentative and Alternative Communication, in press. Doi: 10.3109/07434618.2015.1084042

Kozlowski, L. J., Kost-Byerly, S., Colantuoni, E., Thompson, C. B., Vasquenza, K. J., Rothman, S. K., Billett, C., White, E.D., Yaster M., Monitto, C. L. (2014). Pain prevalence, intensity, assessment and management in a hospitalized pediatric population. Pain Management Nursing, 15, 22-35.

Larnert, P., Risto, O., Hagglund, G., \& Wagner, P. (2014). Hip displacement in relation to age and gross motor function in children with cerebral palsy. Journal of Children's Orthopaedics, 8, 129-134.

Lazarus, R. S. (2006). Emotions and interpersonal relationships: toward a person-centered conceptualization of emotions and coping. Journal of Personality, 74, 9-46.

Morse, J.M. (2015). Critical Analysis of Strategies for Determining Rigor in Qualitative Inquiry. Qualitative Health Research, 25, 1212-1222. 
Nilsson, S., Enskär, K., Hallqvist, C., \& Kokinsky, E. (2013). Active and passive distraction in children undergoing wound dressings. Journal of Pediatric Nursing, 28, 158-166.

Nilsson, S., Johansson, G., Enskär, K., \& Himmelmann, K. (2011). Massage therapy in postoperative rehabilitation of children and adolescents with cerebral palsy - a pilot study. Complementary Therapies in Clinical Practice, 17, 127-131.

Nortjé, N., \& Albertyn, R. (2015). The cultural language of pain: a South African study. South African Family Practice, 57, 24-27.

Novak, I., McIntyre, S., Morgan, C., Campbell, L., Dark, L., Morton, N., Stumbles, E., Wilson, S. A., \& Goldsmith, S. (2013). A systematic review of interventions for children with cerebral palsy: state of the evidence. Developmental Medicine \& Child Neurology, 55, 885-910.

Parkinson, K. N., Gibson, L., Dickinson, H. O., \& Colver, A. (2010). Pain in children with cerebral palsy: a cross-sectional multicentre European study. Acta Pcediatrica, 99, 446-451.

Penner, M., Xie, W. Y., Binepal, N., Switzer, L., \& Fehlings, D. (2013). Characteristics of pain in children and youth with cerebral palsy. Pediatrics, 132, e407-413.

Pin, T. W., Elmasry, J., \& Lewis, J. (2013). Efficacy of botulinum toxin A in children with cerebral palsy in Gross Motor Function Classification System levels IV and V: a systematic review. Developmental Medicine \& Child Neurology, 55, 304-313.

Ramstad, K., Jahnsen, R., Skjeldal, O. H., \& Diseth, T. H. (2011). Characteristics of recurrent musculoskeletal pain in children with cerebral palsy aged 8 to 18 years. Developmental Medicine \& Child Neurology, 53, 1013-1018.

Ramstad, K., Loge, J. H., Jahnsen, R., \& Diseth, T. H. (2014). Self-reported mental health in youth with cerebral palsy and associations to recurrent musculoskeletal pain. Disability and Rehabilitation. 37, 144-50. 
Rivi, E., Filippi, M., Fornasari, E., Mascia, M. T., Ferrari, A., \& Costi, S. (2014).

Effectiveness of standing frame on constipation in children with cerebral palsy: a single-subject study. Occupational Therapy International, 21, 115-123.

Rosenbaum, P., Paneth, N., Leviton, A., Goldstein, M., \& Bax, M. (2007). A report: the definition and classification of cerebral palsy Developmental Medicine \& Child Neurology, 49, 8-14.

Saloojee, G., Phohole, M., Saloojee, H., \& Ijsselmuiden, C. (2007). Unmet health, welfare and educational needs of disabled children in an impoverished South African periurban township. Child: Care Health and Development, 33, 230-235.

Sandelowski, M. (1993). Rigor or rigor mortis: the problem of rigor in qualitative research revisited. ANS Advances in Nursing Sciences, 16, 1-8.

South African Nursing Council. (1984). Regulations Relating to the Keeping, Supply, Administering or Prescribing of Medicines by Registered Nurses. In: http://www.sanc.co.za/regulat/Reg-med.htm.

Swiggum, M., Hamilton, M. L., Gleeson, P., \& Roddey, T. (2010). Pain in children with cerebral palsy: implications for pediatric physical therapy. Pediatric Physical Therapy, 22, 86-92.

Thunberg, G., Buchholz, M., \& Nilsson, S. (2015). Strategies that assist children with communicative disability during hospital stay: Parents’ perceptions and ideas. Journal of Child Health Care. Feb 12. Pii: 1367493514568298. [Epub ahead of print]

Titchen, T., Cranswick, N., \& Beggs, S. (2005). Adverse drug reactions to nonsteroidal antiinflammatory drugs, COX-2 inhibitors and paracetamol in a paediatric hospital. British Journal of Clinical Pharmacology, 59, 718-723.

Twycross, A. (2013). Nurses' views about the barriers and facilitators to effective management of pediatric pain. Pain Management Nursing, 14, e164-172. 
Twycross, A., \& Collis, S. (2013). How well is acute pain in children managed? A snapshot in one English hospital. Pain Management Nursing, 14, e204-215.

Walker, S. P., Wachs, T., Grantham-McGregor, S., Black, M. M., Nelson, C. A., Huffman, S. L., Baker-Henningham, H., Chang, M. S., Hamadani, J. D., Lozoff, B., Meeks Gardner, J. M., Powell, C. A., Rahman, A., \& Richter, L. (2011). Inequality in early childhood: risk and protective factors for early child development. Lancet. 378, 13251338.

Vargus-Adams, J. N., \& Martin, L. K. (2011). Domains of importance for parents, medical professionals and youth with cerebral palsy considering treatment outcomes. Child: care, health and development, 37, 276-281.

Vaughan-Graham, J., Cott, C., \& Wright, F. V. (2015a). The Bobath (NDT) concept in adult neurological rehabilitation: what is the state of the knowledge? A scoping review. Part I: conceptual perspectives. Disability and Rehabilitation, 37, 1793-1807.

Vaughan-Graham, J., Cott, C., \& Wright, F. V. (2015b). The Bobath (NDT) concept in adult neurological rehabilitation: what is the state of the knowledge? A scoping review. Part II: intervention studies perspectives. Disability and Rehabilitation, 37, 1909-1928.

Vles, G. F., Soudant, D. L., Hoving, M. A., Vermeulen, R. J., Bonouvrié, L. A., van Oostenbrugge, R. J., \& Vles, J. S. (2013). Long-term follow-up on continuous intrathecal Baclofen therapy in non-ambulant children with intractable spastic Cerebral Palsy. European Journal of Paediatric Neurology. 17:639-44.

Vogtle, L. K., Malone, L. A., \& Azuero, A. (2014). Outcomes of an exercise program for pain and fatigue management in adults with cerebral palsy. Disability and Rehabilitation, 36, 818-825. 
Westbom, L., Hagglund, G., \& Nordmark, E. (2007). Cerebral palsy in a total population of 411 year olds in southern Sweden. Prevalence and distribution according to different CP classification systems. BMC Pediatrics, 7:41

White, M. A., \& Verhoef, M. J. (2005). Toward a Patient-Centered Approach: Incorporating Principles of Participatory Action Research Into Clinical Studies Integrative Cancer Therapies, 4, 21-24.

Wibeck, V. (2010). Fokusgrupper: om fokuserade gruppintervjuer som undersökningsmetod. Lund: Studentlitteratur.

Wibeck, V., Abrandt Dahlgren, M., \& Öberg, G. (2007). Learning in focus groups: an analytical dimension for enhancing focus group research. Qualitative research, 7, 249267.

Williams, S. A., Elliott, C., Valentine, J., Gubbay, A., Shipman, P., \& Reid, S. (2013). Combining strength training and botulinum neurotoxin intervention in children with cerebral palsy: the impact on muscle morphology and strength. Disability and Rehabilitation, 35, 596-605. 
Table 1. Background information on the participating schools

\begin{tabular}{|c|c|c|c|c|c|}
\hline & School & School & School & School & School \\
\hline & A & B & $\mathrm{C}$ & $\mathrm{D}$ & $\mathrm{E}$ \\
\hline \multicolumn{6}{|l|}{ School information } \\
\hline Ages of children (years) & $13-21$ & $3-21$ & $6-18$ & $3-21$ & $3-21$ \\
\hline Number of children & 506 & 403 & 329 & 372 & 270 \\
\hline Number of children in class (average) & 14 & 16 & 12 & 12 & 15 \\
\hline Number of children with CP & 16 & 106 & 126 & 241 & 100 \\
\hline Proportion of children with CP & $3 \%$ & $26 \%$ & $38 \%$ & $65 \%$ & $37 \%$ \\
\hline Hostel & Yes & Yes & No & Yes & No \\
\hline Number of children in hostel & 506 & 23 & 0 & 102 & 0 \\
\hline Proportion of children in hostel & $100 \%$ & $6 \%$ & --- & $27 \%$ & --- \\
\hline \multicolumn{6}{|l|}{ Staff } \\
\hline Number of educators & 53 & 49 & 28 & 34 & 20 \\
\hline Number of children/educator & 9.5 & 8.2 & 11.8 & 10.9 & 13.5 \\
\hline Number of class assistants per class & 0 & 2 & 0.33 & $1-2$ & 1 \\
\hline Number of therapists & 7 & 21 & 6 & 2 & 8 \\
\hline Number of children/therapist & 72.3 & 19.2 & 54.8 & 186 & 33.8 \\
\hline
\end{tabular}


Table 2. Demographic data of participants

\begin{tabular}{|c|c|c|c|c|c|c|}
\hline & School A & School B & School C & School D & School E & Total \\
\hline $\begin{array}{l}\text { Number of } \\
\text { participants }\end{array}$ & 6 & 8 & 7 & 7 & 10 & 38 \\
\hline $\begin{array}{l}\text { Age of participants } \\
\text { (years) }\end{array}$ & $\begin{array}{c}27-59 \\
(M=43.0 \\
\text { SD 11.4) }\end{array}$ & $\begin{array}{c}33-64 \\
(M=49.6 \\
\text { SD 10.3) }\end{array}$ & $\begin{array}{c}24-58 \\
(M=38.0 \\
\text { SD 14.0) }\end{array}$ & $\begin{array}{c}22-59 \\
(M=44.0 \\
\text { SD13.6) }\end{array}$ & $\begin{array}{c}33-61 \\
(M=45.4 \\
\text { SD 11.3) }\end{array}$ & $\begin{array}{c}22-64 \\
(\mathrm{M}=44.4 ; \\
\text { SD 11.9) }\end{array}$ \\
\hline $\begin{array}{l}\text { Working with } \\
\text { children (years) }\end{array}$ & $\begin{array}{c}5-24 \\
(\mathrm{M}=11.7 \\
\text { SD 8.3) }\end{array}$ & $\begin{array}{c}4-40 \\
(M=22.9 \\
\text { SD 12.0) }\end{array}$ & $\begin{array}{c}\text { 6-32 } \\
(\mathrm{M}=13.1 \\
\text { SD 9.6) }\end{array}$ & $\begin{array}{c}0.2-32 \\
(\mathrm{M}=16.2 \\
\text { SD11.2) }\end{array}$ & $\begin{array}{c}4-35 \\
(\mathrm{M}=15.7 \\
\text { SD 8.7) }\end{array}$ & $\begin{array}{c}0.2-40 \\
(M=16.2 ; \\
\text { SD 10.2) }\end{array}$ \\
\hline $\begin{array}{l}\text { Working with } \\
\text { children with CP } \\
\text { (years) }\end{array}$ & $\begin{array}{c}3-20 \\
(M=7.8 \\
\text { SD 6.3) }\end{array}$ & $\begin{array}{c}4-34 \\
(M=18.9 \\
\text { SD 10.4) }\end{array}$ & $\begin{array}{c}6-23 \\
(\mathrm{M}=10.0 \\
\text { SD 7.3) }\end{array}$ & $\begin{array}{c}3-25 \\
(M=10.8 \\
\text { SD 9.7) }\end{array}$ & $\begin{array}{l}0.1-26 \\
(\mathrm{M}=9.8 \\
\text { SD 8.6) }\end{array}$ & $\begin{array}{c}0.1-34 \\
(\mathrm{M}=11.8 \\
\text { SD 9.2) }\end{array}$ \\
\hline \multicolumn{7}{|l|}{ Profession } \\
\hline Educator & 2 & 2 & 2 & 2 & 3 & 11 \\
\hline Therapist & 4 & 6 & 5 & 5 & 7 & 27 \\
\hline Nurse & 0 & 1 & 1 & 2 & 1 & 5 \\
\hline $\begin{array}{l}\text { Occupational } \\
\text { therapist }\end{array}$ & 1 & 1 & 1 & 0 & 5 & 8 \\
\hline Physiotherapist & 2 & 1 & 1 & 1 & 1 & 6 \\
\hline Psychologist & 0 & 1 & 0 & 0 & 0 & 1 \\
\hline Social worker & 0 & 0 & 1 & 0 & 0 & 1 \\
\hline $\begin{array}{l}\text { Speech/language } \\
\text { therapist }\end{array}$ & 1 & 2 & 1 & 1 & 0 & 5 \\
\hline Personal assistant & 0 & 0 & 0 & 1 & 0 & 1 \\
\hline \multicolumn{7}{|l|}{ Level of education } \\
\hline High school & 0 & 0 & 0 & 1 & 0 & 1 \\
\hline $\begin{array}{l}\text { Higher education } 3 \\
\text { years }\end{array}$ & 1 & 3 & 1 & 0 & 2 & 7 \\
\hline $\begin{array}{l}\text { Higher education } 4 \\
\text { years }\end{array}$ & 4 & 3 & 4 & 5 & 8 & 24 \\
\hline Master’s degree & 0 & 2 & 1 & 1 & 0 & 4 \\
\hline Doctoral degree & 0 & 0 & 1 & 0 & 0 & 1 \\
\hline Unknown level & 1 & 0 & 0 & 0 & 0 & 1 \\
\hline Additional NDT & 0 & 1 & 2 & 0 & 1 & 4 \\
\hline
\end{tabular}

NDT - Neurodevelopmental Therapy 
Table 3. Three main categories of pain management strategies

\begin{tabular}{|c|c|c|}
\hline Environmental strategies & Treatment strategies & Support strategies \\
\hline $\begin{array}{l}\text { Assistive devices } \\
\text { Adaptation of schedule } \\
\text { Peer support } \\
\text { Knowledge transfer from } \\
\text { therapist to educator/ } \\
\text { assistants } \\
\text { Collaboration with parents }\end{array}$ & $\begin{array}{l}\text { Stretching } \\
\text { Positioning } \\
\text { Relaxation } \\
\text { Medication }\end{array}$ & $\begin{array}{l}\text { Distraction } \\
\text { Preparing the child before } \\
\text { treatment } \\
\text { Emotional support and } \\
\text { encouragement of the child } \\
\text { during treatment } \\
\text { Professional team } \\
\text { collaboration } \\
\text { External health care support }\end{array}$ \\
\hline
\end{tabular}


Table 4. Contextual factors affecting pain and participation of children with CP in South African school settings

\begin{tabular}{ll}
\hline Codes & Statements \\
\hline Children's & Children with CP are dedicated. They ignore their pain to do their \\
adjustment to pain & work. They are strong-minded and can concentrate despite the pain. \\
& Children would rather be at school and not be absent for a long time; \\
they therefore do not complain about pain. & \\
& Children have been through a great deal from birth - operations, \\
trauma, etc.; a little tummy ache is nothing. & Parents often take their children to traditional or religious healers \\
instead of physicians or orthopedic doctors. \\
towards disability \\
Parents' frame of reference is different from that of staff and therapists \\
in the school setting. \\
Due to cultural beliefs, especially in rural areas, some people still \\
believe that a disabled child should be hidden from sight and, thereby, \\
not taken to school. \\
Public transport is not disability friendly - children sit for a long time \\
to wait for a taxi, and extra fees have to be paid if the person is in a \\
wheelchair. \\
Professionals' caseloads are huge and overwhelming, prioritizing \\
younger children over older ones - older children are neglected at \\
school but still need maintenance and support, socialization, and \\
communication. \\
Lack of personal assistants, i.e., educators perform the assistants’ work \\
in the classroom. \\
Only private patients use botulinum toxin if they can afford it. Medical \\
aid pays for only two ampoules. \\
New educators no longer get information on the conditions of the \\
learners in the class and on what to expect of them. \\
In general, government hospitals lists are full and the waiting list is \\
very long for children to get help. \\
Resources
\end{tabular}

